IMECE2006-14197

\title{
CASCADED CONTROL FOR REGULATING SOOT GEOMETRY IN VAPOR-PHASE AXIAL DEPOSITION
}

\author{
Hodge E. Jenkins \\ Dept. of Mechanical and Industrial Engineering \\ Mercer University \\ 1400 Coleman Ave. \\ Macon, GA 31207 USA \\ JENKINS_HE@Mercer.edu
}

\author{
Mark L. Nagurka \\ Dept. of Mechanical Engineering \\ Marquette University \\ P.O. Box 1881 \\ Milwaukee, WI 53201 -1881 USA \\ mark.nagurka@marquette.edu
}

\begin{abstract}
The development of a cascaded feedback control strategy for a vapor-phase axial deposition (VAD) process is investigated in this paper. VAD is a widely used process in the creation of high purity glass for optical fiber. In previous work a soot tip surface temperature controller was developed for the VAD process to reduce the effects of core soot temperature variation on deposition, leading to a more stable process. However, this approach did not address the need to regulate and link the deposition rates of the core and clad torches. To maintain a constant distance between the core and clad deposition surfaces, it is desired to have the core soot and clad soot depositing at the same linear speed to provide a more uniform product. This paper presents the design and development of a cascaded controller strategy and process model to couple and regulate the surface temperature and deposition rates of core and clad soot. Simulations for the process and control scheme demonstrate a potential improvement in the uniformity of the core and clad soot geometry over the soot product length.
\end{abstract}

\section{INTRODUCTION}

This paper investigates a process control improvement for a vapor-phase axial deposition (VAD) process, a commonly used process for the manufacture of high quality glass for optical fiber. The process deposits a glass soot mixture of silicon-dioxide and germanium-dioxide to create the light guide core and cladding around the core. It is desirable to maintain the core and clad geometry to create a uniform product, necessary for high bandwidth optical transmission and costeffective production. Common practice in the VAD process is for the core and clad soot deposition rates, as well as the related surface temperature, to run essentially open-loop while regulating constant flow rates of gases and chemicals. This leads to varying diameters of core and clad soot regions which affect the usable length of the final glass.

VAD was invented at NTT Laboratories in Japan and is the dominant process for Japanese manufacturers of optical fiber. VAD is an improvement on the Corning OVD (outside vapor deposition) process [1,2]. Much has been written and documented about the VAD process (Refi [3], Choi [4], MacChesney [5]). However, developments in modeling and control of the process are still actively pursued in industry [6].

VAD is a multi-step process for creation of high purity glass soot for optical fiber. This work focuses on the creation of the soot preform step. Soot making and deposition are typically accomplished via two torches in a vertical process chamber with a rotating chuck (Fig. 1). A core torch creates circular inner core soot from a mixture of germanium-dioxide, silicon-dioxide, oxygen, and fuel (typically hydrogen). A pure silicon-dioxide soot layer is also concurrently deposited from a second (clad) torch, as part of the final cladding around the core. The germanium-dioxide component of the core region increases the refractive index of the light guide core over the index of the surrounding cladding glass in the resulting optical fiber. (Basic glass chemistry and flame hydrolysis reactions for the glass process in VAD are available in several references [3, $4,7])$.

The rotating chuck moves upward as glass soot is deposited to form a preform. The preform moves upward by a control loop using laser light to indicate the tip position. As the soot core tip grows, it blocks the light signal and causes the servo stage to move upward. This upward movement is commonly referred to as pull speed. The pull speed is a result 
of position control on the core tip to keep it in the same location as the soot preform grows. Thus, the pull speed is the core soot deposition linear growth rate. In contrast, the cladding growth is not controlled. After the soot preform has reached the design length (1m or larger) a sequential sintering operation is used to consolidate the glass soot to form a solid glass preform, nearly ready to draw into optical fiber.

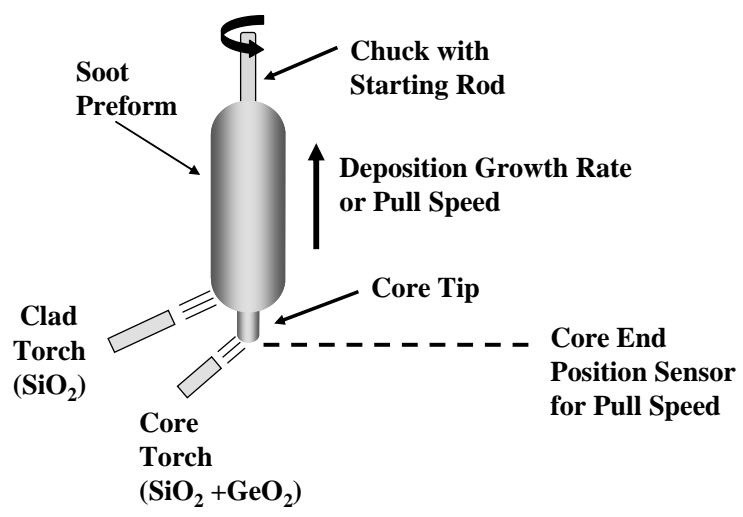

Figure 1. VAD process: core and clad torches

\section{PROBLEM DESCRIPTION}

Common practice in VAD processing is for the core and clad soot deposition rates, as well as the related surface temperature, to run essentially open-loop. Each deposition torch (core and clad) has regulated flow rates of chemicals and gases (determined a priori by trial and error approaches). While the goal is to perfectly match the depositions of the clad and core, it is rarely accomplished. The core region may grow faster than the clad, or vice versa. In addition to causing the soot preform tip length to grow or to shrink, relative to the cladding, this situation causes the diameter ratios of the clad to core $(\mathrm{D} / \mathrm{d})$ to vary. This $(\mathrm{D} / \mathrm{d})$ variation results in a less uniform product requiring more processing or waste. These diameters and variations can be visualized in Fig. 2. Final soot performs show open-loop process variation as indicated by the non-uniform or tapering outside diameters or varying length core tips.

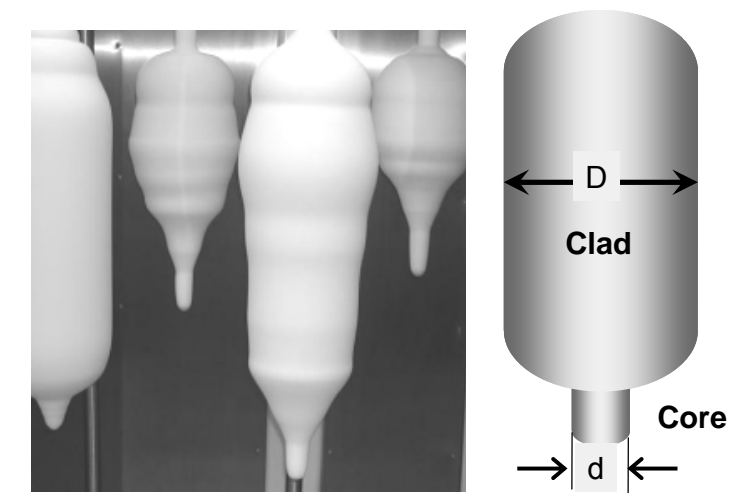

Figure 2. Variation in soot outside diameters and core tip length. (Core tip diameters depicted are nominally $40-\mathrm{mm}$.)
Thus, keeping the core tip length constant will, in effect, result in matching soot growth rates for the core and clad regions. As depicted in Fig. 3, the core tip length $\left(\mathrm{L}_{\mathrm{CORE}}\right)$ can be determined by the time integral of the (deposition) growth rates of the core and clad sections of the soot preform, $\dot{X}_{\text {CORE }}$ and $\dot{X}_{C L A D}$, respectively, eq. (1).

$$
L_{C O R E}=L_{o}+\int \dot{X}_{C O R E} d t-\int \dot{X}_{C L A D} d t
$$

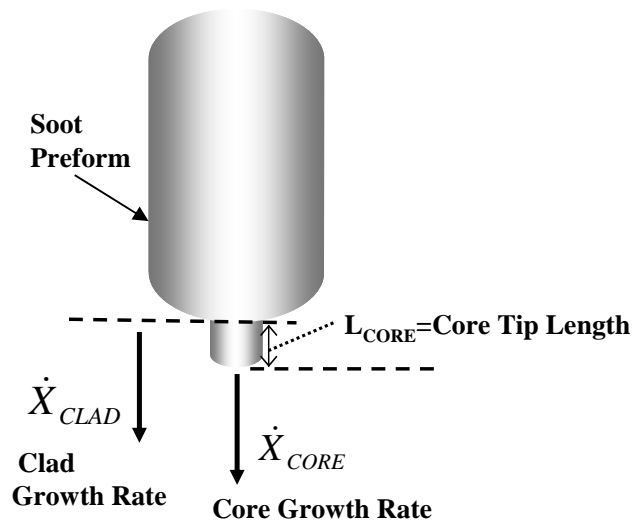

Figure 3. Core and clad growth rate for soot perform

It will be shown that the core soot substrate tip temperature can be used to control the core deposition rate (pull speed) and ultimately the core tip length (between the core and clad deposition surfaces). The core deposition rate was shown to be controllable by the $\mathrm{H}_{2}$ flow to the core torch [8]. Therefore, control of the core tip length may be accomplished by slowing or increasing the rate of the core deposition, $\dot{X}_{\text {CORE }}$, while leaving the clad deposition rate constant.

In earlier work [8] a soot tip surface temperature controller was developed for the VAD process to reduce the effects of core soot temperature variation on deposition, leading to a more stable process. However, this approach did not address the need to regulate and link the deposition rates of the core and clad torches. It is desired to have the core soot and clad soot depositing at the same speed so that the core and clad deposition surfaces maintain a constant distance between each other, thereby providing a more uniform product.

Presented in this paper is the design and development of a controller to couple and regulate the core surface temperature and the resulting core soot deposition rate. Simulations for the process control demonstrate a potential improvement in the uniformity of the core and clad soot geometry over the soot length. It should be noted that the clad deposition rate can be measured by a variety of available, low cost devices, including optical phototransistors or machine vision.

\section{SOOT DENSITY}

As presented by $\mathrm{Li}$ [7], the crystalline structure for the $\mathrm{GeO}_{2}$ and $\mathrm{SiO}_{2}$ soot mixture found in the core region is not completed while in the deposition torch flame, and it has been 
shown to be dependent on the substrate temperature. The $\mathrm{GeO}_{2}$ structure of the mixture is all crystalline below $400^{\circ} \mathrm{C}$. However, the $\mathrm{GeO}_{2}$ soot deposited between $500^{\circ} \mathrm{C}$ and $800^{\circ} \mathrm{C}$ has a linearly increasing percentage of non-crystalline forms of $\mathrm{GeO}_{2}$ mixed with the $\mathrm{SiO}_{2}$. The non-crystalline forms of $\mathrm{GeO}_{2}$ have a higher soot density which causes the linear speed of core soot growth to decrease given constant mass flow rates of $\mathrm{GeCl}_{4}$ and $\mathrm{SiCl}_{4}$ to the torch. This phenomenon has also been observed in experiments as changes in pull speed corresponding to changes in the core substrate temperature as seen in Fig. 4. The resulting approximately linear relationship between pull speed and substrate temperature can be utilized to provide a model for a control scheme.

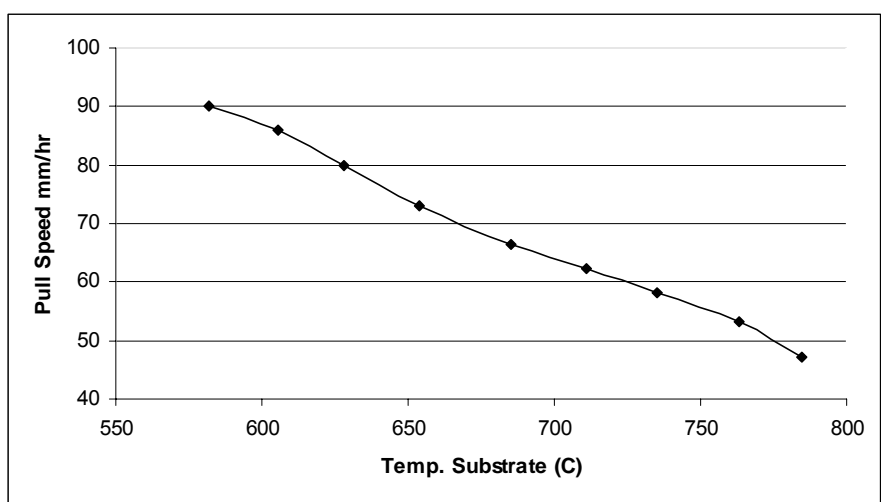

Figure 4. Pull speed (core growth rate) vs. substrate temperature

If the core and clad linear growth rates are not equal, two situations may occur. First, if the core growth rate is faster than the clad rate, then the core tip length will growth and outrun the clad causing a tapered effect on the cladding outside diameter (see Fig. 2). As the core moves further away from the cladding deposition location less heat is transferred from the cladding to the core tip. The lower temperature of the core substrate decreases the soot density and causes even faster pull speeds for the core, aggravating the situation. The second possible situation is for the clad growth rate to be larger than the core growth rate. The cladding torch deposits faster than the core torch causing the cladding surface to engulf the core tip making a bulging diameter. As the core tip length is very short in this case, the heat flux from the clad deposition increases as the core surface gets nearer the core tip. The density of the core soot increases with temperature causing the core pull speed to slow even further. The system can become somewhat unstable.

To address this mismatch of growth rates a cascaded controller is proposed to change the core deposition temperature set point based on the growth rates of the core and clad. A diagram of the desired cascaded control scheme is given in the functional block diagram of Fig. 5 .

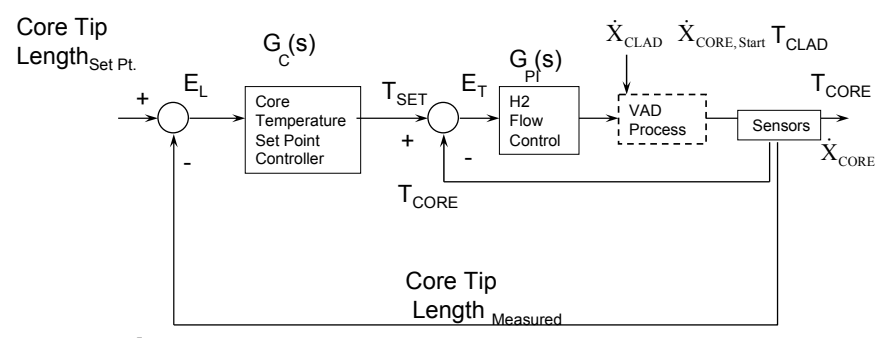

Figure 5. VAD cascaded control scheme

\section{MODEL DEVELOPMENT}

In order to gain insight into the process and explore potential control schemes, a model of the VAD process described is developed. Growth rates or pull speeds of $50 \mathrm{~mm} / \mathrm{h}$ or higher are common in industry [9]. Therefore, a nominal design based on $65 \mathrm{~mm} / \mathrm{h}$ is presented.

In this work a VAD core substrate temperature model (eq. (2)) and $\mathrm{H}_{2}$ flow control, $\mathrm{G}_{\mathrm{PI}}(\mathrm{s})$ (eq. (3)), developed in earlier work [8], were employed as part of the system model. A plot of experimental data and the identified model output to a $0.25 \mathrm{l} / \mathrm{m}$ step input in $\mathrm{H}_{2}$ flow is provided in Figure 6. A first order model was deemed the most appropriate approximation of the core substrate temperature response to $\mathrm{H}_{2}$ flow change. (The temperature data contain substantial noise from the flame movement under exhaust gas ventilation flow.)

$$
\frac{\Delta T_{\mathrm{CORE}, \mathrm{H} 2}(s)}{\Delta H_{2}(s)}=G_{P}(s)=\frac{a}{s+b}\left[{ }^{\circ} \mathrm{C}-\mathrm{m} / \mathrm{l}\right]
$$

where $\mathrm{a}=7.51, \mathrm{~b}=0.0778$

$$
G_{P I}(s)=K_{p}\left(s+\frac{K_{i}}{K_{p}}\right) \frac{1}{s}\left[1 /{ }^{\circ} \mathrm{C} / \mathrm{m}\right] ;
$$

where $\mathrm{K}_{\mathrm{i}} / \mathrm{K}_{\mathrm{p}}=0.065$ and $\mathrm{K}_{\mathrm{p}}=0.035$
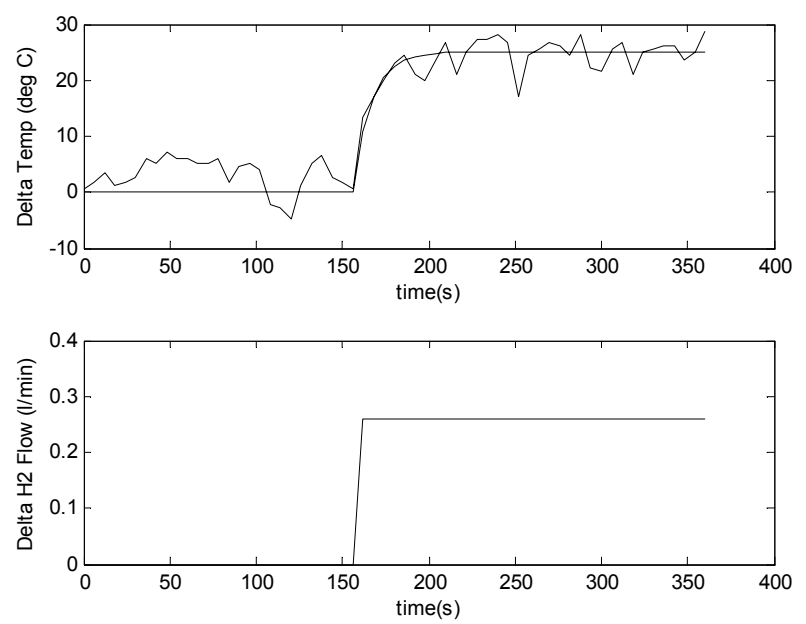

Figure 6. Temperature output: Model and process data (top); Step input of $\mathrm{H}_{2}$ flow (bottom) 
This VAD process model is expanded here to include the effects of the changing core substrate temperature as a function of the core tip length. There are several assumptions in this model. The heat fluxes from both the clad and core torches are assumed constant. This permits modeling of the core substrate temperature as a function of the distance between the heated clad substrate and the core substrate. As the clad torch gas/chemical flow rates are substantially (approximately an order of magnitude) higher than the core torch, the clad torch temperature is treated as unaffected by its proximity to the core torch. The core torch has little influence on the clad deposition rate, as can be seen in Fig. 7. Based on these assumptions a suitable process model of the VAD Process model can be developed to address core substrate temperature changes and core tip growth. It should be noted that the thermal model presented here is a very simplistic model and not a rigorous thermal analysis with appropriate complex boundary conditions. The model is designed to provide basic insight into a potential control scheme.

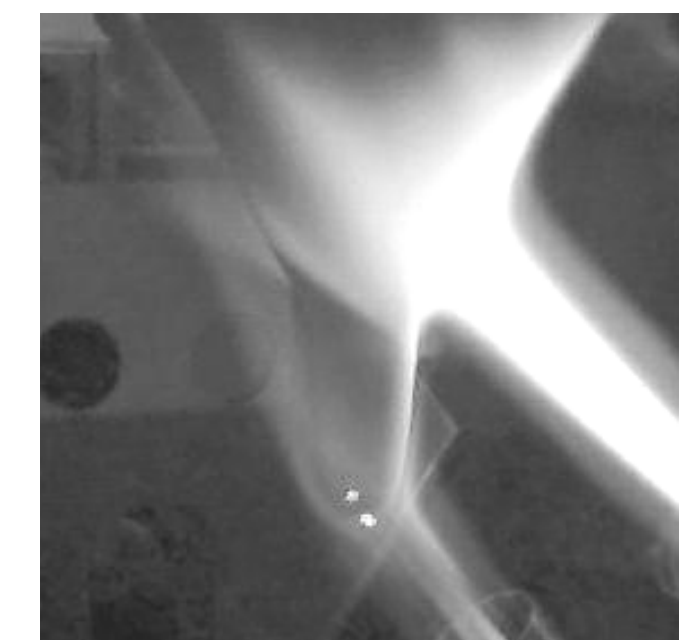

\section{Figure 7. Typical Core and Clad Deposition in VAD Process}

The clad torch has a relatively constant temperature $\left(T_{C L A D}\right)$ and heat flux $\left(\mathrm{q}_{\mathrm{CLAD}}\right)$. The variation of the core substrate temperature $T_{\text {CORE }}$, thermal conductivity, $k_{T H}$, and the core substrate tip length, $L_{C O R E}$, can be modeled as follows: (Note: $T_{C L A D}$ is higher than $T_{C O R E}$.)

$$
\begin{gathered}
\frac{q_{C L A D, S S}}{A}=k_{T H}\left[\frac{T_{C L A D}-T_{C O R E}}{L_{C O R E}}\right]_{S S} \approx \text { constant }=\beta \\
L_{C O R E}=L_{0}+\Delta L, L_{0}=50 \mathrm{~mm}
\end{gathered}
$$

$$
\begin{gathered}
T_{C O R E}=T_{C L A D}-\frac{q_{C L A D, S S}}{A}\left(\frac{L_{C O R E}}{k_{T H}}\right) \\
T_{C O R E}=T_{C L A D}-\frac{\beta\left(L_{0}+\Delta L\right)}{k_{T H}} ; \text { where } \beta=\text { constant }
\end{gathered}
$$

Thus the change in $T_{\text {CORE }}$ from the growth in the core tip length is given in eq. (8).

$$
\Delta T_{\text {CORE }_{-} L E N G T H}=\frac{\beta(\Delta L)}{k_{T H}}
$$

The core substrate temperature, $T_{C O R E}$, can be viewed as the superposition of the temperature generated by the core torch combustion heat flux, $T_{C O R E, H 2}$ and the change caused by the heat flux from the higher temperature clad substrate region with the change in core tip length, $\Delta T_{\text {CORE_LENGTH }}$.

$$
T_{\text {CORE }}=T_{\mathrm{CORE}, H_{2}}+\Delta T_{\mathrm{CORE}_{-} L E N G T H}
$$

The thermal conductivity of $\mathrm{SiO}_{2}$ is dependent on structure and temperature. For a ceramic structure the thermal conductivity is linear, as depicted in Fig. 8. A linear fit of the thermal conductivity vs. temperature data yields eq. (10).

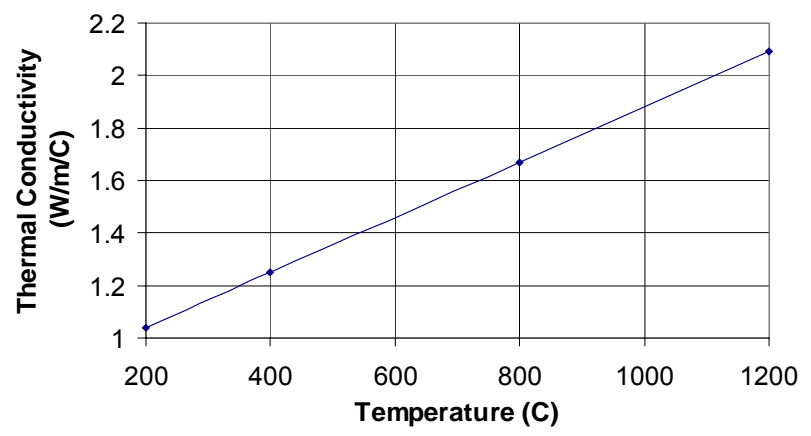

Figure 8. Thermal conductivity of ceramic $\mathrm{SiO}_{2}[10]$

$$
k_{T H}=0.83+(0.00105) \mathrm{T}\left[\mathrm{W} / \mathrm{m}^{\mathrm{o}} \mathrm{K}\right\rfloor
$$

where $T=0.5\left(T_{\mathrm{CORE}}+T_{\mathrm{CLAD}}\right)$.

Using eq. (2) through eq. (10) a simple thermal model can be developed to represent the core substrate temperature as a function of heat flux, clad temperature, core torch $\mathrm{H}_{2}$ flow, and core length. 


\section{VAD process model}

A block diagram of the system model of the core substrate temperature and deposition growth, based on the previously discussed assumptions and presented data, is provided in Fig. 9.

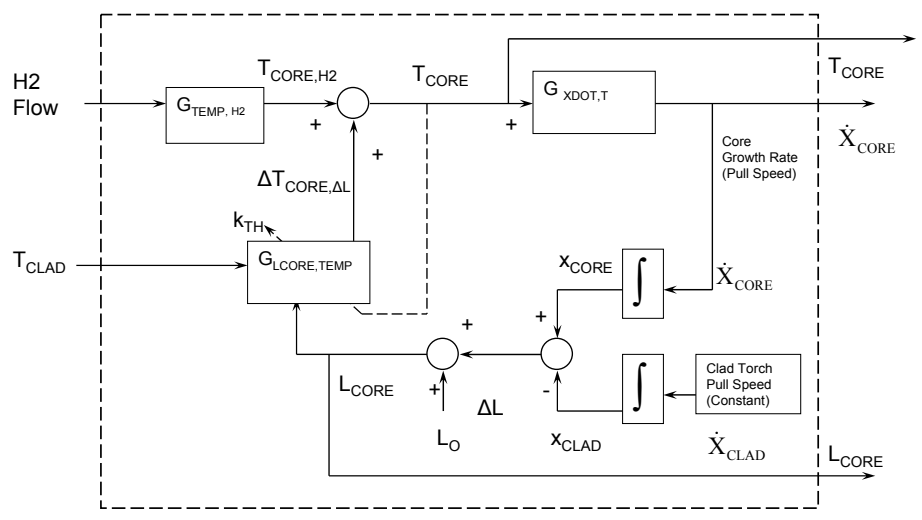

Figure 9. System model of the core substrate temperature and growth

A regression (with an $r^{2}$ value of 0.993) of the pull speed vs. temperature data of Fig. 4 yields the following relationship,

$$
\dot{X}_{\text {CORE }}=210.46-0.20783 \cdot T_{\text {CORE }}
$$

for core growth as a function of time. In eq. (11), growth rate is expressed in $\mathrm{mm} / \mathrm{h}$ and temperature is in ${ }^{\circ} \mathrm{C}$.

\section{Model Response Open Loop}

A model was created with Simulink ${ }^{\mathrm{TM}}$ (MathWorks) using the process equations previously described. The simulation had intentionally mismatched growth rates for the clad and core torches $(60 \mathrm{~mm} / \mathrm{h}$ and $65 \mathrm{~mm} / \mathrm{h}$, respectively). The core substrate temperature set point and initial condition was $700^{\circ} \mathrm{C}$ while the clad substrate temperature was a constant $850^{\circ} \mathrm{C}$. The previous temperature control [8] was implemented to regulate core substrate temperature. No control was applied to the core tip length, $L_{C O R E}$. As a result the core tip length grew linearly from $40-\mathrm{mm}$ to 60 -mm over 4-hours of deposition, as expected with the $5-\mathrm{mm} / \mathrm{h}$ mismatch in clad and core deposition rates, and maintaining core substrate temperature. Fig. 10 depicts these results.
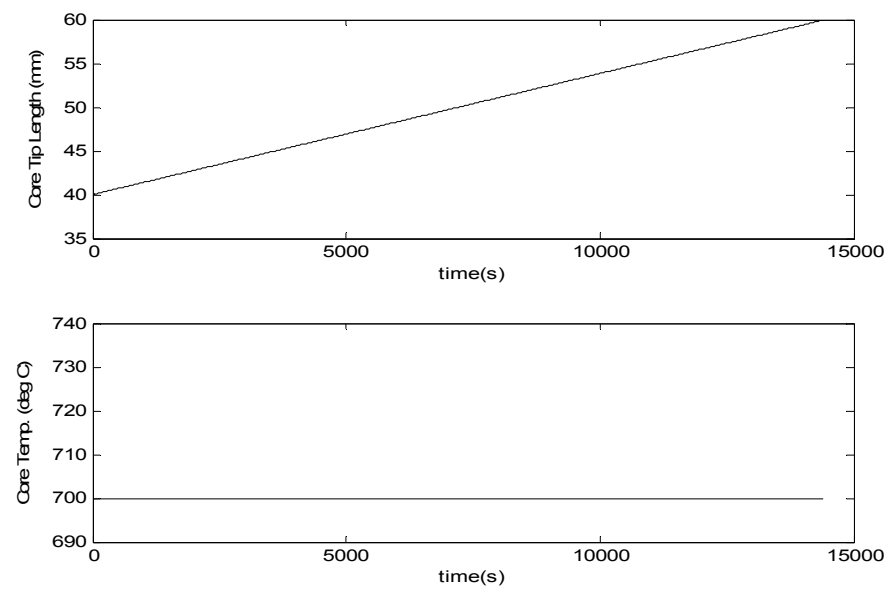

Figure 10. Open-Loop response of VAD process: core tip temperature (top); core tip substrate temperature (bottom).

\section{CASCADED CORE TIP LENGTH CONTROL}

\section{Initial control design}

As the core tip length can be considered a first order system (essentially an integral function), dependent upon the mismatch of the clad and core deposition rates, proportional control of sufficiently high gain can be used to control the process. Other design considerations are the sampled system stability and sensor noise.

It should be noted that negative gains were required for the core tip controller. This was because of how the core tip length error affects the core tip growth. When the core tip is too long, the core tip length error is negative and reduces the temperature set point. The reduction in temperature decreases soot density and further increases core growth rate, making the situation worse. The correct controller outcome reduces the soot density with an increase in core substrate temperature set point for a negative length error. Likewise, a decrease in the core substrate temperature set point corresponds to a positive length error. Thus, a negative controller gain is required to not have a 'real' positive feedback situation.

\section{SIMULATIONS \& RESULTS}

Figure 11 depicts the simulated closed-loop response for core tip length and core substrate temperature as functions of time, using several gain values for proportional control in the core tip length controller. The core tip length and the core temperature both respond as first order systems. The process was able to achieve a constant core length, after a period of time.

Depending on the proportional gain, there was a small, steady state error. With a simple proportional controller and a gain magnitude of $10^{\circ} \mathrm{C} / \mathrm{mm}$ the core tip length grew from 40 $\mathrm{mm}$ to $42.4-\mathrm{mm}$ over a 4-hour simulation. A gain magnitude of 
$800^{\circ} \mathrm{C} / \mathrm{mm}$ produces a faster time system time constant. A core tip length of $40.03-\mathrm{mm}$ was also obtained. Clearly, the larger gain produced the most desirable results.
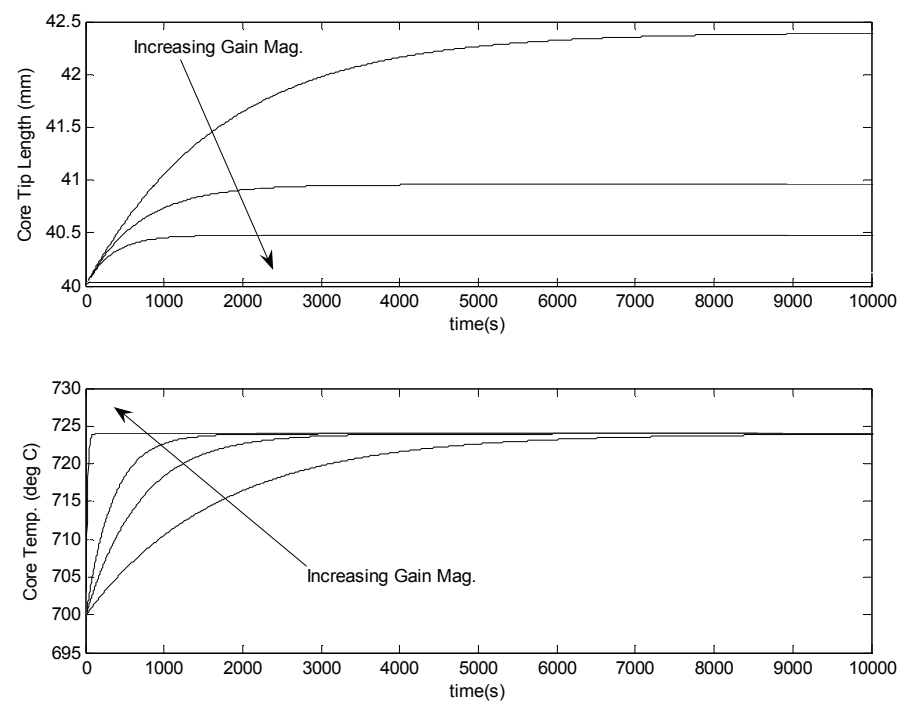

Figure 11. Closed-loop response of VAD process: core tip temperature (top); core tip substrate temperature (bottom). Proportional control gain magnitudes of $10,25,50,200$, and $800^{\circ} \mathrm{C} / \mathrm{mm}$.

Modeling of filtered $(0.15 \mathrm{~Hz})$ random sensor noise of $\pm 0.02 \mathrm{~mm}$ for the core tip length sensor indicates that a gain of $800^{\circ} \mathrm{C} / \mathrm{mm}$ yields substantial disturbances in the core temperature. (This is depicted in Fig. 12(a).) However, this sensor and temperature disturbance does not translate to the significant core length variation. Still a reduction in the proportional gain to $200^{\circ} \mathrm{C} / \mathrm{mm}$ and the addition of a very small integral gain reduces the temperature variation, while keeping the length error within acceptable limits.
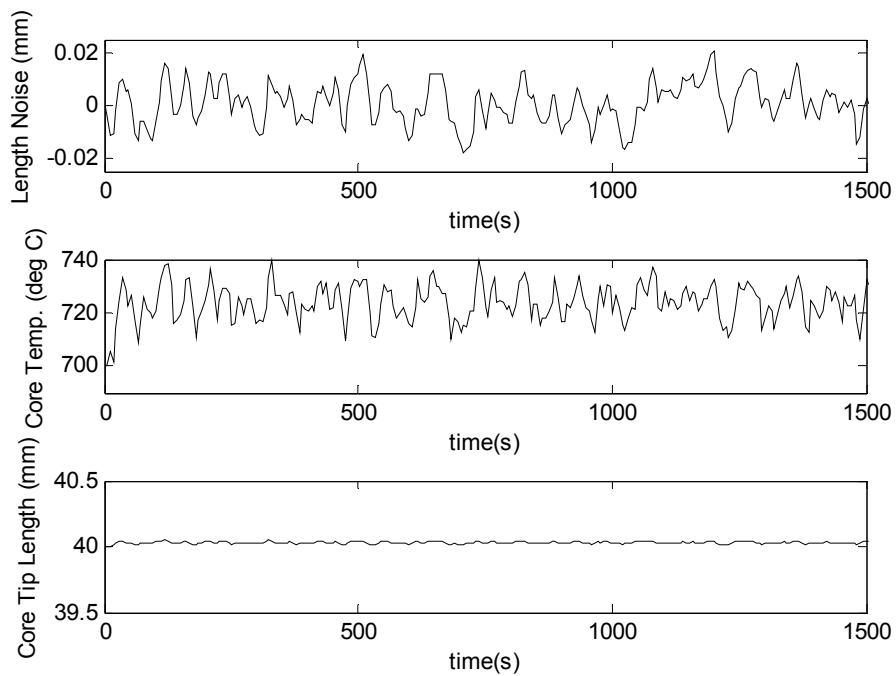

Figure 12 (a) P-control $800^{\circ} \mathrm{C} / \mathrm{mm}$
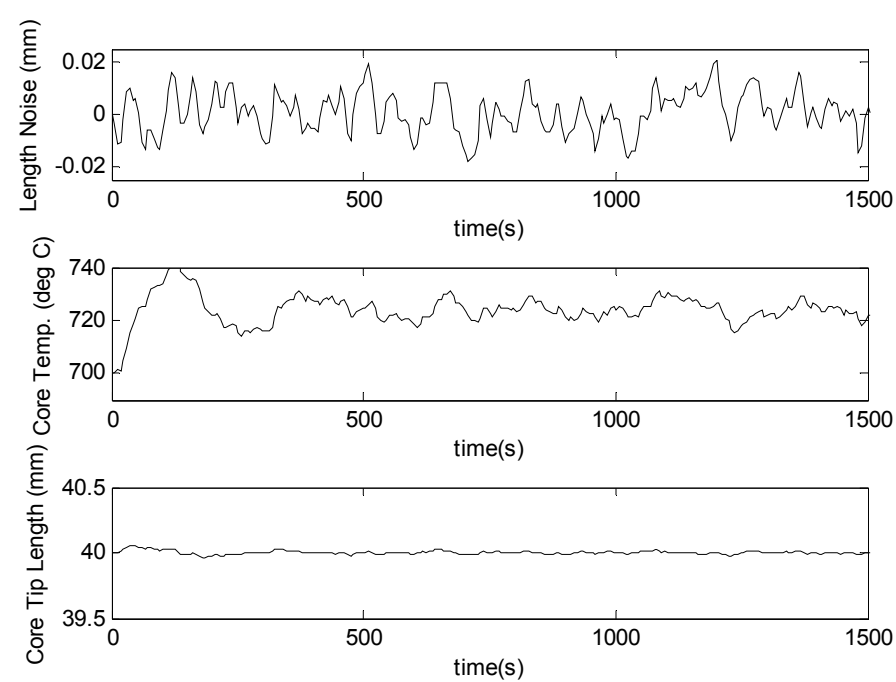

Figure 12 (b) $\mathrm{PI}-$ Control $200^{\circ} \mathrm{C} / \mathrm{mm}$

Simulation of closed loop system with sensor noise: sensor noise (top), temperature (middle), core tip length (bottom)

\section{SUMMARY AND CONCLUSIONS}

A closed-loop scheme for cascaded control of core tip length and core substrate temperature has been successfully modeled and simulated. A marked decrease in the potential for mismatch between core and clad soot deposition rates underlying soot core tip variations is indicated by the model developed in this paper. The control of the core tip length forces the deposition rates of the core and clad to be matched. The simulated model results of this work indicate a significant potential improvement in the obtainable geometry of soot preforms. The cascaded-controller proposed appears to be relatively straight-forward to implement.

No actuator saturation has been observed in the system model. Also, since the time constant of the controlled system is relatively slow, a broad spectrum of controllers would be suitable.

It should be noted that the achievable system performance of the proposed control scheme may be less than the model predicts, and dependent upon sensor noise, other unmodeled disturbances, and unmodeled system complexities. While a proportional control of the core length appears adequate, a PI controller may do as well or better in this situation to reduce the steady-state error with less gain. The simulation studies raise further modeling questions, and strongly suggest tests via experimental implementation.

\section{NOMENCLATURE}

A Area, effective heat flow normal area

D Clad diameter of glass preform

d Core diameter

$\mathrm{G}_{\mathrm{P}}$ (s) Plant transfer function from $\mathrm{H} 2$ (s) to $\mathrm{T}_{\mathrm{CORE}}(\mathrm{s})$

$\mathrm{G}_{\mathrm{PI}}(\mathrm{s}) \quad \mathrm{PI}$ controller transfer function for $\mathrm{H} 2$ flow 


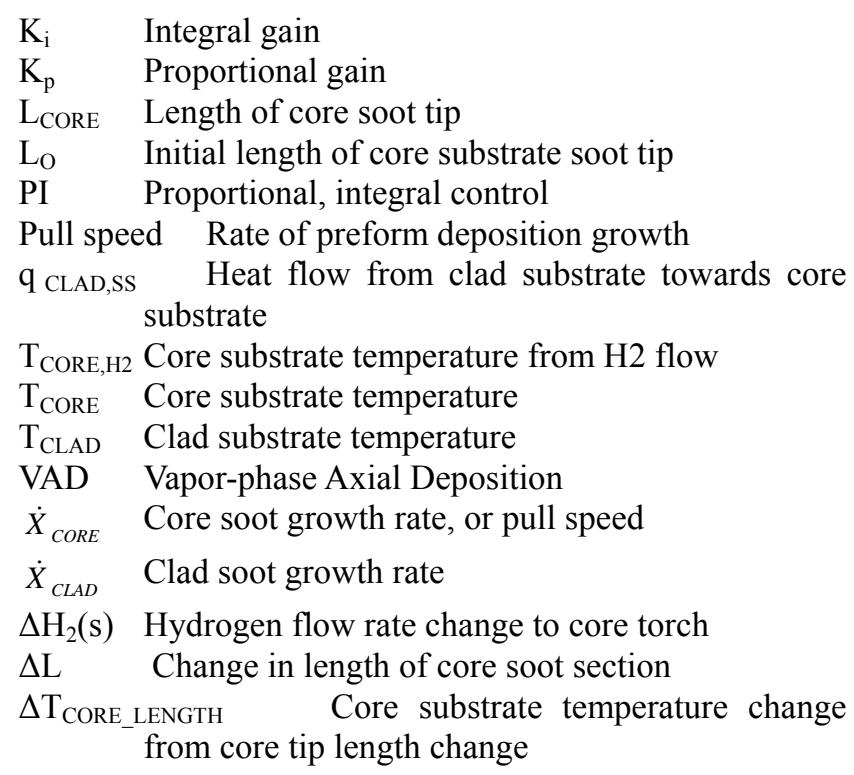

\section{REFERENCES}

[1] Izawa, T., Miyashita, T. and Hanawa, F., 1977, "Continuous fabrication of high silica fiber preform," U.S. Patent 4,062,665.

[2] Keck, D.B, Schultz, P.C., Zimar, F., 1973 "Method of forming optical waveguide fibers," U.S. Patent 3,737,292.

[3] Refi, J., 1991, Fiber Optic Cable: A Light Guide, ABC Teletraining, Geneva, IL.

[4] Choi, M., Park, J.S., and Cho, J., 1995, "Modelling of Chemical Vapour Deposition for Optical Fiber," Opt. Quantum Electron., 27(5), pp. 327-335.

[5] MacChesney, J.B., O'Connor, P.B., and Presby, H. M., 1974, "A New Technique for the Preparation of Low-Loss and Graded Index Optical Fibers,” Proc. IEEE, 62(9), pp. 1282-3.

[6] MacChesney, J.B. and DiGiovanni, D.J., 1990, "Materials Development of Optical Fiber," J. of the American Ceramic Soc., 73(12), pp. 3537.

[7] Li, T. (Ed.), 1985, Optical Fiber Communications, Vol. 1, Academic Press, Inc., Orlando, FL.

[8] Jenkins, H.E and Radharamanan, R.., 2006, "Closed-Loop Control in the VAD Process: A Case Study for Modeling and Control," 2006 Int. Symposium on Flexible Automation, Osaka, Japan.

[9] Suda, H., Sudo, S.,Nakahara, M .,1983 "Fine glass particledeposition mechanism in the VAD process," Fiber Integrated Opt., 4(4), pp. 427-437.
[10] Shakelford, J.F., and Alexander, W., (ed.), 2001 CRC Materials Science and Engineering Handbook, CRC Press, Boca Raton, FL, pp.284. 